\title{
Investigación clínica en hematología y oncología en América Latina
}

\author{
Clinical research in hematology and oncology in Latin America
}

\author{
- Andrés Felipe Cardona', Diana Rivera², Andrés Acevedo³ \\ 'Editor jefe RCHO \\ 2 Editor ejecutivo RCHO \\ ${ }^{3}$ Asistente del editor RCHO
}

En general, se considera que la contribución de América Latina a la producción científica global es baja, incluyendo la generación de conocimiento en áreas sensibles de la hematología y la oncología. Un análisis bibliométrico de la geografía relacionada con la producción literaria, presentada en las reuniones anuales de la Sociedad Americana de Oncología Clínica (ASCO, por su sigla en inglés), indicó que cerca de la mitad de los resúmenes provienen de los Estados Unidos; de igual forma, el estudio documentó que cerca del $20 \%$ de los países latinoamericanos en dicha conferencia cada año producen más del $90 \%$ de los estudios aceptados. El mejor representante de nuestro entorno fue Brasil, que constituyó el 1.1\% (IC 95\% 0.34\% - 1.46\%); tal cifra fue inferior a lo reportado por China, Corea del Sur, Canadá, España, Francia, Alemania, Japón, Italia y Estados Unidos'.

Los estudios desarrollados en múltiples países e instituciones correspondieron tan solo al $15 \%$ de las referencias, encontrando una tendencia temporal creciente para este estadístico, que indicó una mayor colaboración multilateral. El intercambio fue positivo entre los países con mayor desarrollo económico, e incluyó ocasionalmente otras naciones con menor proyección científica pero con una economía más sólida (China, India, Turquía, Brasil).

En concordancia, un análisis multivariado demostró que las variables relacionadas con los estudios clínicos de mejor calidad se asociaron con el número de instituciones participantes, la fase del experimento clínico, el apoyo irrestricto de la industria farmacéutica, la nacionalidad de origen y la relación con instituciones provenientes de Estados Unidos'.

En el pasado, Ugolini y colaboradores valoraron 66.000 artículos relacionados con cáncer, publicados entre 1996 y 2000, hallando que el 35\% provenían de
Europa y el $40 \%$ de Estados Unidos; el factor de impacto medio de la producción editorial Europea fue de 2.9, mientras el estadounidense fue de 4.0, cifras que demostraron la distribución ponderal de la información en nuestras especialidades a nivel mundial².

En Colombia, Rosselli y colaboradores recolectaron las referencias citadas en Medline generadas entre 1987 y 1996, descubriendo un número de 531, lo que implicó una producción anual para el país de 53 textos/año, concentrados en cuatro universidades ${ }^{3}$. Con el objeto de determinar la frecuencia de las presentaciones relacionadas con la investigación biomédica en hematología y oncología provenientes de las naciones latinoamericanas, Acevedo y colaboradores llevaron a cabo un estudio que incluyó los resúmenes publicados entre el 1 de enero de 2000 y el 31 de marzo de 2011, en ASCO, ASH, ESMO y ASTRO, considerando cada referencia como la unidad de caso que debió tener relación con investigación básica, clínica o de transferencia (información en prensa).

El rastreo se expandió en la internet con la intención de encontrar la publicación o publicaciones formales derivadas de la investigación, usando las plataformas PubMed, Embase, Lilacs y la sección académica de Google. Después de analizar 2.625 referencias, se seleccionaron 1.858 para evaluación y extracción de datos, con un error muestral inferior al $10 \%$. El estudio permitió documentar que la mayoría de las referencias provenían de ASCO y ASH, asociaciones en las que se encontró un incremento en la producción científica latinoamericana de 397\% y $114 \%$, respectivamente.

Cinco países (Brasil, Argentina, México, Perú y Chile) concentraron el $96.3 \%$ de la literatura, siendo dominante el papel de Brasil (51\%), Argentina (20\%) y México (14\%). Lamentablemente, Colombia sólo aportó 
el $1.3 \%$, con un crecimiento ponderal para la década del $218 \%, 2.4$ y 4 veces menor que lo encontrado para Perú y Brasil en el mismo periodo, respectivamente. A pesar del esfuerzo, solamente el $17.4 \%$ de las referencias se publicó en revistas que tuvieron un factor de impacto promedio de 3.5, evento que ocurrió 1.6 años después de la presentación original y que permitió alcanzar 14 citas luego de su indización.

Estos datos invitan a la reflexión con la intención de generar espacios que favorezcan la calidad y visibilidad de nuestros conceptos, hallazgos relacionados con la intimidad, el fomento de la colaboración y el deseo continuo de crear una academia más generosa alrededor de las ciencias afines a la hematología y la oncología.

Los editores invitan a todos aquellos interesados en compartir el conocimiento local a incrementar la representatividad de la Asociación Colombiana de Hematología y Oncología en el entorno científico global, a través de su medio escrito, la Revista Colombiana de Hematología y Oncología.

\section{Referencias}

1. Saad ED, Mangabeira A, Masson AL, Prisco FE. The geography of clinical cancer research: analysis of abstracts presented at the American Society of Clinical Oncology Annual Meetings. Ann Oncol. 2010;21(3):627-32
2. Ugolini D, Mela GS. Oncological research overview in the European Union. A 5-year survey. Eur J Cancer. 2003;39(13):1888-94.

3. Rosselli-Cock D. La investigación biomédica en Colombia: un análisis de Medline. Colombia Médica. 1998;29(2-3):108-11.

\section{Ciencia y cáncer}

\section{Cancer and science}

\section{- José Félix Patiño Restrepo (Hon)*}

*Jefe Honorario, Departamento de Cirugía

Fundación Santa Fe de Bogotá

En el devenir histórico y en el avance científico de la medicina, el desarrollo de las especialidades y las subespecialidades (¿más bien superespecialidades?) constituye hitos y marca campos definidos del saber biomédico.

En las vastas y crecientes áreas de la medicina interna, la hematología y la oncología representan causas muy frecuentes de consulta. Las entidades patológicas del sistema hematolinfopoyético, benignas y malignas, afectan a todas las edades y constituyen hoy áreas de investigación, con resultados fructíferos para beneficio de los pacientes. Enfermedades, en niños y en adultos, que hasta hace pocas décadas eran incurables, hoy son tratadas en forma exitosa, con largos periodos de vida libre de enfermedad o con curación definitiva.

El desarrollo del trasplante de medula ósea, perfeccionado luego al de células progenitoras periféricas, constituye un avance de singular importancia.

Las especialidades combinadas de la oncología y la hematología se han fundido, por decirlo así, en una nueva superespecialidad, la Hemato-Oncología. La Asociación Colombiana de Hematología y Oncología $(\mathrm{ACHO})$ ha señalado áreas prioritarias en sus planes y programas de desarrollo, y desde hace años mantiene un activo y exitoso programa de generación de conocimiento.

En buena hora la $\mathrm{ACHO}$ ha decidido iniciar esta publicación, que viene a llenar un vacío en nuestro país y en los países de habla hispana. Las enfermedades que comprenden los campos de la oncología y la hematología son causa principal de morbilidad, y de mortalidad prematura -o sea la mortalidad que ocurre en niños y en adultos en las etapas productivas de la vida-, en Colombia y en América Latina.

Mantener actualizado el conocimiento es obligación para el médico, y esta nueva publicación, con una lujosa dirección editorial, se convierte en un poderoso instrumento de educación continuada y de estímulo a la investigación y la superación de la docencia. 